\title{
A toponímia no estado de Minas Gerais: estudo dos zootopônimos
}

\author{
Cassiane Josefina de Freitas \\ Universidade Federal de Minas Gerais (UFMG), Belo Horizonte, Minas Gerais, Brasil \\ cassianej@yahoo.com.br
}

DOI: http://dx.doi.org/10.21165/el.v46i1.1691

\begin{abstract}
Resumo
Este artigo trata de estudo descritivo preliminar - linguístico e cultural - dos topônimos (nomes próprios de lugar) de índole animal presentes no estado de Minas Gerais. A exuberância da fauna brasileira, assim como seu papel fundamental à sobrevivência dos primeiros indivíduos, é revelada no expressivo número de topônimos de origem animal. Com a intenção de verificar a preferência regional pelo emprego sistemático dessas denominações em território mineiro, surgiu a ideia de desenvolver o presente trabalho.
\end{abstract}

Palavras-chave: cultura; léxico toponímico; zootoponímia.

\section{The toponymy in Minas Gerais state: study of animal toponymy}

\begin{abstract}
This article deals with preliminary descriptive study - linguistic and cultural of - place names (first names of place) of animal nature present in the state of Minas Gerais. The exuberance of Brazilian fauna, as well as its key role for the survival of the first individuals, are revealed in the expressive number of toponyms of animal origin. It was with the intention of verifying the regional preference for the systematic use of these names in Minas Gerais's territory, that the idea of developing this work emerged.
\end{abstract}

Keywords: culture; toponymic lexicon; animal toponymy.

\section{Introdução}

O presente trabalho apresenta resultados preliminares relativos à pesquisa de doutorado em andamento, que consiste em investigar e descrever a zootoponímia (nomes de lugares motivados por nomes de animais) presente no território mineiro e terá como finalidade contribuir para as investigações linguístico-culturais referentes à língua portuguesa no Brasil.

O estudo dos nomes de lugar possibilita a identificação e a recuperação de fatos linguísticos recorrentes no ato denominativo. Os topônimos testemunham parte da história da língua, já que os contatos linguísticos e culturais entre os povos são registrados e conservados através dos signos linguísticos.

A língua é um fato social que evidencia as particularidades com que cada comunidade vê e representa o mundo. A linguagem é, ao mesmo tempo, manifestação primária do social, do "ser com o outro" do homem, e a língua não é "obrigatória" como imposição externa, mas como obrigação livremente assumida (COSERIU, 1983, p. 29). Esse caráter social da língua faz com que a veiculação de ideias e experiências seja favorecida e reforce a interação entre os membros de uma sociedade. Segundo Oliveira (1999), a língua funciona como um elemento de interação entre o indivíduo e a 
sociedade em que ele atua. A língua e o comportamento linguístico dos falantes estão, assim, ligados à cultura e às relações sociais.

Dizer que existem palavras que estão relacionadas deiticamente com algum "objeto" ou aspecto do mundo significa reconhecer que as palavras levam consigo um poder que vai além da descrição e identificação de um povo, dos objetos, das propriedades e dos acontecimentos, significa tratar de identificar os modos como a língua se transforma em uma ferramenta através da qual nosso mundo social e cultural é descrito, evolui e se reproduz constantemente (DURANTI, 2000, p. 43, tradução nossa) ${ }^{1}$.

O processo de nomeação, por sua vez, é um ato designativo constituído através da relação entre ambiente, povo e cultura. Sendo assim, essa inter-relação homemambiente também é representada pela linguagem. Segundo Carvalhinhos e Antunes (2007), a questão do nome sempre foi foco de inúmeras análises, como a da relação semântica entre um objeto, o conceito e a forma da palavra. O gramático Dionísio, ainda de acordo com os referidos autores, já formulara tais questões na Grécia do século II a.C., ele descrevera o onoma quando ainda não havia conceito de nome próprio como concebemos hoje, que se opõe ao nome comum.

Os filósofos gregos do tempo de Sócrates, e, em seguida, Platão, propuseram a questão nos termos em que ela geralmente se propõe até hoje. Para eles a relação semântica que liga as palavras às coisas é a de "denominar"; e a questão que daí decorre é a de saber se os "nomes" dados às "coisas" eram de origem "natural" ou "convencional". No curso do desenvolvimento da gramática tradicional, tornou-se hábito distinguir entre o significado da palavra e a "coisa" ou as "coisas" por ela "denominadas" (LYONS, 1979, p. 427).

Para Biderman (1998), a atividade de nomear é específica da espécie humana. A nomeação é o resultado do processo de categorização, que é, ainda segundo a autora, a classificação de objetos feita por um sujeito humano, "resultando numa única resposta a uma determinada categoria de estilos do meio ambiente".

A designação é, pois, uma possibilidade da linguagem que se fundamenta na linguagem como significação. E a designação é o que nos conduz ao mundo das coisas que, em consequência, como mundo "estruturado" (diferenciado de tais ou tais "classes de coisas"), só pode ser alcançado mediante a linguagem. A linguagem possibilita, portanto, o acesso ao extralinguístico, às próprias coisas. Pode por isso ser também instrumento da vida prática, que é precisamente a convivência no mundo extralinguístico. Mas ainda mais importante e essencial é o fato de a linguagem tornar acessíveis as coisas à investigação objetiva, razão pela qual pode ser ela considerada como princípio e base primeira da ciência. Dito de outra maneira, o mundo das coisas (ou "objetos") está dado ao homem, mas só através do mundo dos significados: através da configuração linguística. E é a linguagem que proporciona "objetos" às ciências: às ciências do geral, objetos como "árvore", "peixe"; à história dos objetos como "Pedro", "Roma"; à filosofia, objetos como "verdade", "virtude" (COSERIU, 1982, p. 27).

\footnotetext{
1 "Decir que hay palabras que están relacionadas deícticamente con algún < objeto> o aspecto del mundo significa reconocer que las palabras llevan consigo un poder que va más allá de la descripción e identificación de la gente, los objetos, las propriedades o los acontecimientos. Significa tratar de identificar los modos con los que la lengua se convierte en una herramienta a través de la cual nuestro mundo social y cultural se describe, evalúa y reproduce constantemente.”.
} 
É o vocabulário que melhor reflete o ambiente físico e social dos que falam. Sendo assim, pode-se afirmar que as palavras são como "etiquetas" para o processo de categorização. Os estudos de natureza lexical se ocupam em estabelecer, organizar e veicular os signos na relação entre o homem e o mundo que o rodeia. Proporcionam um "maior conhecimento da língua falada, ao mesmo tempo em que nos proporcionam o reconhecimento das diferenças culturais que compõem a realidade de um país." (CRISTIANINI; ENCARNAÇÃO, 2008, p. 7).

Os dados que formam nosso corpus foram retirados do banco de dados do projeto ATEMIG (Atlas Toponímico do Estado de Minas Gerais) da Faculdade de Letras da Universidade Federal de Minas Gerais (FALE/UFMG). Um dos objetivos desse trabalho concentra-se no reconhecimento dos remanescentes lexicais na rede toponímica do estado de Minas Gerais, cuja origem remonta a nomes portugueses, indígenas, africanos, dentre outros.

\section{Onomástica e Toponímia}

Onomástica é a ciência da linguagem que se ocupa do estudo dos nomes próprios. Está integrada à lexicologia, que objetiva estudar, categorizar e estruturar as palavras dentro do universo lexical.

A Antroponímia e a Toponímia são subáreas da Onomástica. A Antroponímia se ocupa do estudo dos nomes próprios individuais, os nomes parentais ou sobrenomes e as alcunhas e apelidos. A Toponímia, por sua vez, investiga o léxico toponímico, por meio do estudo da motivação dos nomes próprios de lugares (SEABRA, 2006, p. 1953). Segundo Seabra (2006, p. 1953), ambas se constituem de elementos linguísticos que conservam antigos estágios denominativos.

De acordo com Dick (2006, p. 96), Toponímia e Antroponímia são duas faces de um mesmo rosto maior ou corpo maior: a Onomástica, cujo objeto de trabalho é o nome próprio genericamente considerado, a partir da definição do onoma. Está justamente no onoma o ponto de encontro da Antroponímia com a Toponímia. A palavra, ao deixar seu uso pleno na língua transmitido para um uso onomástico, reveste-se de caráter denominativo - em uso dêitico ou anafórico - e passa a ser referenciada como topônimo ou antropônimo, seguindo direções opostas, mas que se complementam (DICK, 1999, p. 145).

A Toponímia é um ramo da onomástica que se ocupa em estudar a expressão linguístico-social que reflete aspectos culturais de um núcleo humano existente ou preexistente, além de propor o resgate da atitude do homem diante do meio, através do estudo da motivação dos nomes próprios de lugares. Leite de Vasconcelos (1931) define Toponímia como o estudo dos nomes de sítios, de povoações, de nações, de rios, de montes, de vales etc. - isto é, os nomes geográficos. Já Salazar-Quijada (1985) a define como ramo da Onomástica que se ocupa do estudo integral no espaço e no tempo, dos aspectos: geo-históricos, sócio-econômicos, antropo-linguísticos, que permitiram e permitem que um nome de lugar se origine e subsista.

Dick (1990b, p. 119), entretanto, contempla as duas definições supracitadas, evidenciando seu caráter inerentemente interdisciplinar: 
O conceito tradicional de Toponímia envolve o significado etimológico do próprio vocábulo (do gr. topos, "lugar" e onoma, "nome"), qual seja, o estudo dos nomes de lugares ou dos designativos geográficos, em sua bipartimentação física (rios, córregos, morros, etc.) e humana, antrópica, ou cultural (aldeias, povoados, cidades, etc.).

Dick afirma, ainda, que a Toponímia é, antes de tudo, um imenso complexo linguo-cultural, em que dados das demais ciências se interseccionam necessariamente e, não, exclusivamente. Devendo ser considerado, em sua função intrínseca, um fato do sistema das línguas humanas, já que nos permite conhecer aspectos sócio-históricos e culturais presentes e pretéritos da comunidade.

A nomenclatura de uma região encerra, na tipicidade de suas designações, amplas possibilidades de estudo. A tessitura toponímica, com efeito, longe está de ser monótona no significado que recobre ou destituída de interesse prático ou científico. Através das camadas onomásticas, revelam-se, numa perspectiva globalizante, as feições características do local, sejam as de ordem física quanto socioculturais. De tal modo esses aspectos se corporificam nos topônimos que se pode mesmo, muitas vezes, estabelecer a correlação entre o "nome" dos acidentes e o "ambiente" em que ele se acha inscrito. (DICK, 1990b, p. 35).

Os topônimos, que são originalmente extraídos de uma língua viva, são enunciados linguísticos que passam pelo crivo do denominador que os seleciona e interpreta segundo seus conceitos, valores, intenções, códigos e usos que representam também seu grupo. Para Dick (1998), o topônimo, funcionalmente, apresenta-se com uma dupla marca linguística, exercendo não apenas um papel sígnico no universo do discurso, mas também o de suporte de identificação: sugere pistas, indica caminhos interpretativos, torna-se evidência de comportamentos extintos, resgate de memórias vivenciadas.

Segundo Carvalhinhos (2002-2003, p. 172), uma área toponímica pode ser comparada a um sítio arqueológico: podemos reconstruir, através do estudo de significados cristalizados de nomes de lugar, fatos sociais desaparecidos, contribuindo com material valioso para outras disciplinas, como a história, a geografia humana e a antropologia.

Assim como um fóssil descoberto pela paleontologia, o maior ou menor grau de "descoberta" ou "achado valioso" depende da antiguidade do nome cristalizado em determinado momento da oralidade [...]. Descreve-se, assim, a tendência conservadora do topônimo. (CARVALHINHOS, 2002-2003, p. 173.).

\section{Projeto ATEMIG}

O ATEMIG - Atlas Toponímico do Estado de Minas Gerais - é um projeto que teve início em 2005 vinculado à Faculdade de Letras da Universidade Federal de Minas Gerais, sob a orientação da Professora Doutora Maria Cândida Trindade Costa de Seabra. O projeto segue os pressupostos teórico-metodológicos propostos pelo francês Dauzat (1926), adaptados à realidade brasileira por Dick (1990a; b) e detalha a realidade toponímica de todo o território mineiro. 
Partilhando de metodologia comum, adotada pelas demais equipes de pesquisadores que seguem o modelo do ATB em outros estados, o projeto mineiro segue: i) o "método das áreas" utilizado por Dauzat, que propõe o remapeamento da divisão municipal, de acordo com as camadas dialetais presentes na língua padrão; ii) a distribuição toponímica em categorias taxionômicas que representam os principais padrões motivadores dos topônimos no Brasil, sugerida por Dick (1990a; b).

São objetivos básicos do ATEMIG (SEABRA, 2012, p. 73-74):

1. Construir um corpus com todos os topônimos presentes nas cartas geográficas do IBGE, correspondentes a 853 municípios mineiros;

2. Catalogar e reconhecer remanescentes lexicais na rede toponímica mineira cuja origem remonta a nomes portugueses, africanos, indígenas, dentre outros;

3. Classificar e analisar o padrão motivador dos nomes, resultante das diversas tendências étnicas registradas (línguas indígenas, africanas e de imigração);

4. Buscar influência das línguas em contato no território (fenômenos gramaticais e semânticos);

5. Cartografar nomes de acidentes físicos e humanos do Estado de Minas Gerais;

6. Realizar gravações orais com o objetivo de coletar outros topônimos que não constam na rede toponímica oficial do estado;

7. Analisar a toponímia de mapas antigos que remetem ao território mineiro;

8. Realizar estudos diacrônicos a partir dos dados coletados;

9. Construir glossários toponímicos;

10. Estudar os nomes de logradouros (bairros, ruas, praças, becos etc.) presentes em cidades mineiras.

A coleta de dados dos 853 municípios mineiros foi feita seguindo divisão proposta pelo IBGE (Instituto Brasileiro de Geografia e Estatística), que faz o mapeamento do estado em 12 mesorregiões. Esse sistema de divisão é fundamental à elaboração de políticas públicas e de subsídio ao sistema de decisões referentes à localização de atividades econômicas, sociais e tributárias no estado. Contribui, ainda, para as atividades de planejamento, estudos e identificação das estruturas espaciais de regiões metropolitanas e outras formas de aglomeração urbanas e rurais. 


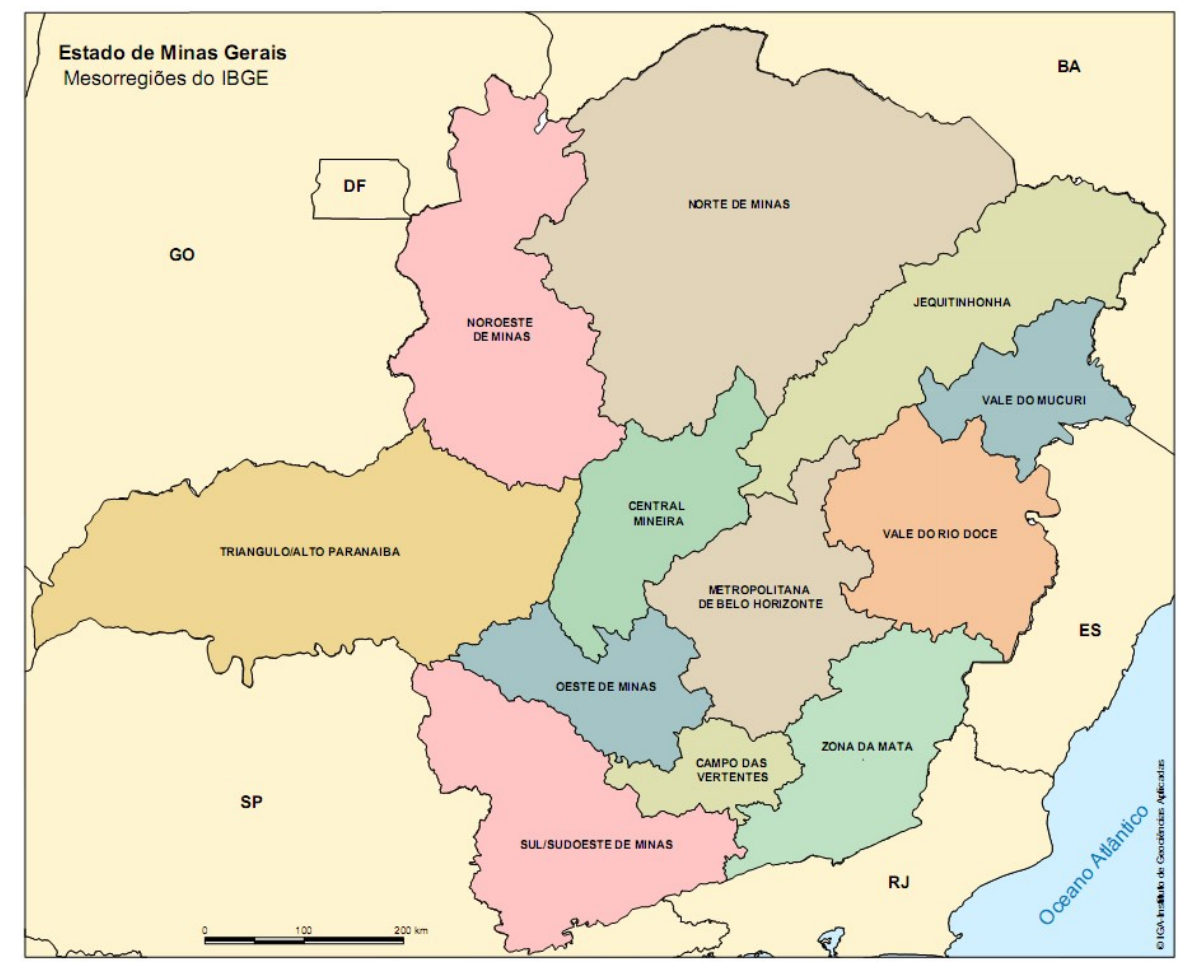

Mapa 1. Lista de mesorregiões de Minas Gerais

Foram levantados, então, em cada mesorregião, todos os nomes de cidades, vilas, povoados, fazendas, rios, córregos, ribeirões, morros, serras, dentre outros acidentes geográficos - físicos e humanos - dos 853 municípios de Minas Gerais, documentados em cartas topográficas - fontes do IBGE, com escalas que variam de 1:50.000 a 1:250.000, perfazendo, até o presente momento, um total de 85.391 topônimos. Após a coleta e catalogação desses dados, os topônimos foram registrados em fichas, conforme modelo sugerido por Dick (2004), para serem analisados e classificados. Essas fichas constituem uma análise - linguística e cultural - detalhada do topônimo, com informações que integram a sociedade e a cultura.

\section{Etapas metodológicas}

Como apresentado anteriormente, o presente trabalho tem como base os pressupostos teóricos dos estudos lexicais, fundamentados na relação entre língua, cultura e sociedade. Foram assumidas as orientações teóricas de Sapir (1961) e Matoré (1953). O primeiro por enfatizar o papel relevante dessa correlação para os estudos da linguagem, destacando o léxico como nível linguístico que melhor revela o ambiente físico e social dos falantes; e o segundo teórico por definir a palavra não como um objeto isolado, mas como parte de uma estrutura social, já que o léxico se torna testemunha de uma época ao refletir as distintas fases que marcam a história de uma sociedade.

As análises relativas à variação e mudança linguística, linha de pesquisa à qual o trabalho em andamento está vinculado, estão sendo realizadas sob a orientação teórica de Labov (1974). O teórico americano foi "quem, mais veementemente, voltou a insistir na relação entre língua e sociedade e na possibilidade, virtual e real, de se sistematizar a 
variação existente e própria da língua falada" (TARALLO, 2007, p. 7). Labov propôs um modelo teórico metodológico que, levando em conta a relação existente entre língua e sociedade, era capaz de sistematizar a variação natural da língua ao longo de diferentes períodos da história. Assim, propomos observar os dados toponímicos em mapas contemporâneos e históricos (séculos XVIII e XIX), a fim de realizar a comparação dos dados.

A investigação toponímica é a base norteadora da nossa pesquisa; para realizála, nos apoiamos nas teorias de Dauzat (1926) e Dick (1990a, 1990b, 2004, 2006), que propõem modelo teórico-metodológico toponímico de origem indutivo-dedutiva, segundo os procedimentos onomasiológico-semasiológicos característicos da pesquisa lexical.

Segundo Dick (2006), o modelo construído para a investigação toponímica propriamente dita não difere do método científico de análise em geral e dos princípios de metodologia aceitos. Para a autora, tal modelo envolve, sistematicamente, três pontos: a) formulação da hipótese de trabalho, ou de uma proposição de estudos, cuja finalidade perseguida é verificar as possibilidades de realização do tema escolhido, já enunciando as etapas admissíveis para esse exame; b) delimitação da área básica de estudos (nível da toponímia) ou do objeto da investigação (nível da onomástica), detalhamento temático, em extensão areal (nível quantitativo) ou em profundidade (nível qualitativo), de acordo com a disponibilidade do pesquisador; c) tratamento dos dados ou do corpus; d) conclusão e bibliografia utilizada e suporte.

[...] a metodologia seguida em uma análise toponímica envolve aspectos da própria construção do texto onomástico, em geral, resguardadas as proporções do alcance de cada um deles. Enquanto um tem por concepção uma visão mais teórica, ampla e abrangente do conhecimento científico advindo dos que representam outra maneira de se estudar a língua e suas variações; o outro busca o conhecimento prático das parcialidades locais/regionais, segundo os modelos teóricos propostos, visando a (re)construção de uma tipologia onomástica de aplicação mais ampla, a partir de novas formas recolhidas (DICK, 2006, p. 101).

Como a presente pesquisa se constitui a partir de uma investigação toponímica, seguimos o roteiro abaixo proposto pela autora:

a) partimos, inicialmente, da hipótese de que, em Minas Gerais, o emprego dos nomes de animais na toponímia relaciona-se diretamente com o processo de povoamento do estado;

b) de maneira vinculada ao Projeto ATEMIG - Atlas Toponímico do Estado de Minas Gerais - há a verificação de como se dá a distribuição geográfica dos zootopônimos nas doze mesorregiões mineiras, a partir da coleta e organização de topônimos que constam do banco de dados do Projeto, constituindo, assim, um corpus de dados contemporâneos.

O projeto ATEMIG (FALE/UFMG) tem realizado o detalhamento e a análise da realidade toponímica de todo território mineiro, seguindo os pressupostos teóricometodológicos de Dauzat (1926) e Dick (1990a, 1990b).

Os dados levantados foram registrados em tabelas que especificam o tipo de acidente geográfico, a origem etimológica do nome e a distribuição toponímica em 
categorias taxionômicas. Parte desses itens já foi catalogada em fichas lexicográficas toponímicas, de acordo com modelo proposto por Dick (2004).

Os topônimos que constituíram o corpus da pesquisa são provenientes do banco de dados do Projeto ATEMIG, do qual serão extraídos todos os nomes de caráter animal, ou zootopônimos, segundo a taxionomia proposta por Dick (1990). Segundo apresentação anterior, os zootopônimos compõem os topônimos de natureza física, conforme podemos observar no esquema a seguir:

Os zootopônimos se subdividem em três grupos: os domésticos - topônimos referentes a animais criados pelo homem para uma certa finalidade, o que implica em que sua reprodução e genética são controlados. Ex: Fazenda Cachorro, Córrego do Boi, Córrego da Novilha Brava; os não domésticos - topônimos referentes a animais que habitam seus ecossistemas de origem, constituindo populações sujeitas à seleção natural, cuja reprodução e genética não foram controladas pelo homem. Ex: Ribeirão do Guará, Lagoa Jacaré, Córrego do Onça -; os grupos - topônimos referentes a grupos de animais da mesma espécie. Ex: Ribeirão da Boiada; Vacaria.

Para a coleta dos nomes, conforme metodologia pré-estabelecida no projeto ATEMIG, serão utilizadas cartas geográficas do IBGE que propõem a divisão territorial dos 853 municípios mineiros em 12 mesorregiões.

\section{Análise de dados}

Em todo o território mineiro, constatou-se a ocorrência de 5.570 zootopônimos, que correspondem a 361 bases léxicas distintas. Observa-se que a origem predominante de tais nomes é a indígena, mais especificamente o tupi, seguida pela origem portuguesa e africana, como nos mostra o gráfico a seguir:

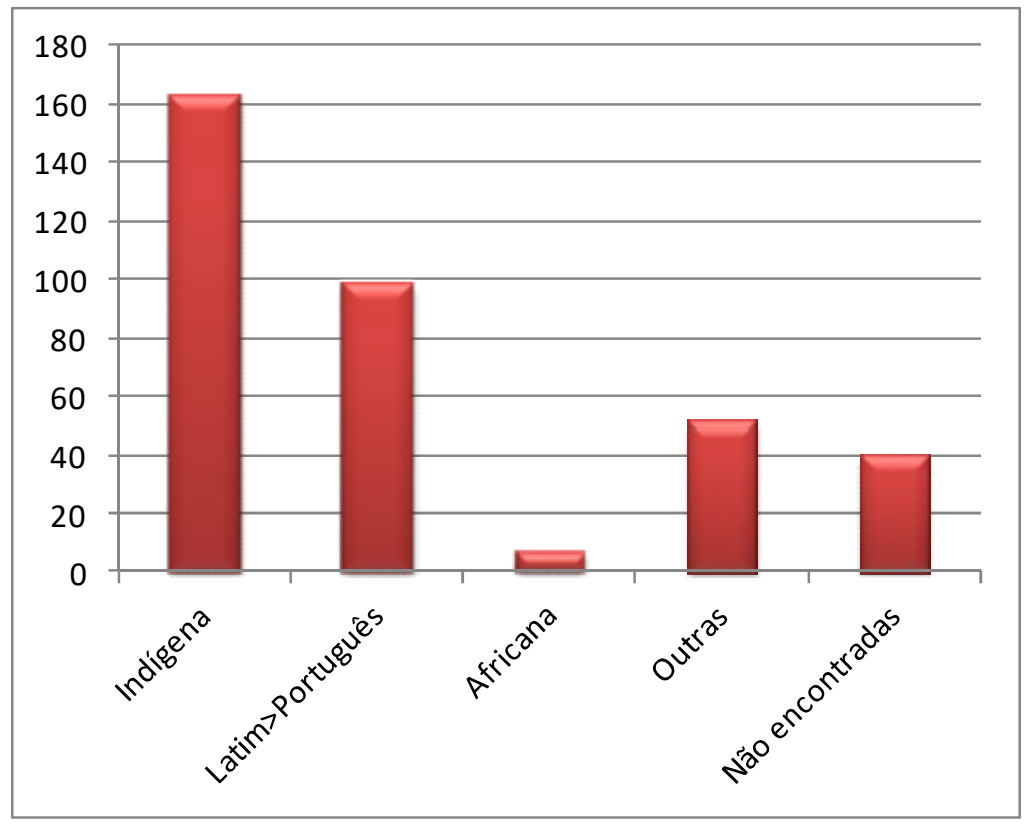

Gráfico 1. Origem dos Topônimos 
Dos 361 nomes contabilizados, 163 são de origem tupi, o que corresponde a $45 \%$ do total de dados registrados. Tal predominância pode ser justificada pelo fato de o indígena ser o primeiro conhecedor da fauna brasileira, cabendo-lhe apresentá-la ao colonizador. Em seguida, estão os topônimos de origem portuguesa, com 99 ocorrências ou $28 \%$ dos nomes. Em número bem menos expressivo, estão os nomes de origem africana, com apenas sete ocorrências (2\%). Outras origens, como a árabe e a francesa, por exemplo, correspondem a 52 ocorrências. Cabe ressaltar que os dados aqui apresentados são oriundos de pesquisa em andamento, portanto, nos faltam maiores esclarecimentos acerca de bases léxicas cuja origem ainda não foi determinada, que representam 40 ocorrências dos dados levantados.

A etimologia dos topônimos pesquisados, até então, foi determinada por consulta às seguintes obras lexicográficas, cujas informações mais detalhadas encontram-se na bibliografia ao final deste artigo:

i) Aurélio Séc. XXI: o dicionário da língua portuguesa, de Aurélio Buarque de Holanda Ferreira;

ii) Dicionário Eletrônico Houaiss da língua portuguesa, de Antônio Houaiss;

iii) Dicionário Etimológico Nova Fronteira da Língua Portuguesa, de Antônio Geraldo da Cunha;

iv) O Tupi na Geografia Nacional, de Teodoro Sampaio;

v) Contribuição Indígena ao Brasil, do Irmão José Gregório.

As bases léxicas selecionadas, referentes aos zootopônimos mineiros, também foram analisadas segundo a categoria ou família à qual pertence o animal. Dada a riqueza da fauna brasileira, há o registro de múltiplas categorias, predominando a dos mamíferos, seguida por aves e peixes, conforme gráfico a seguir:

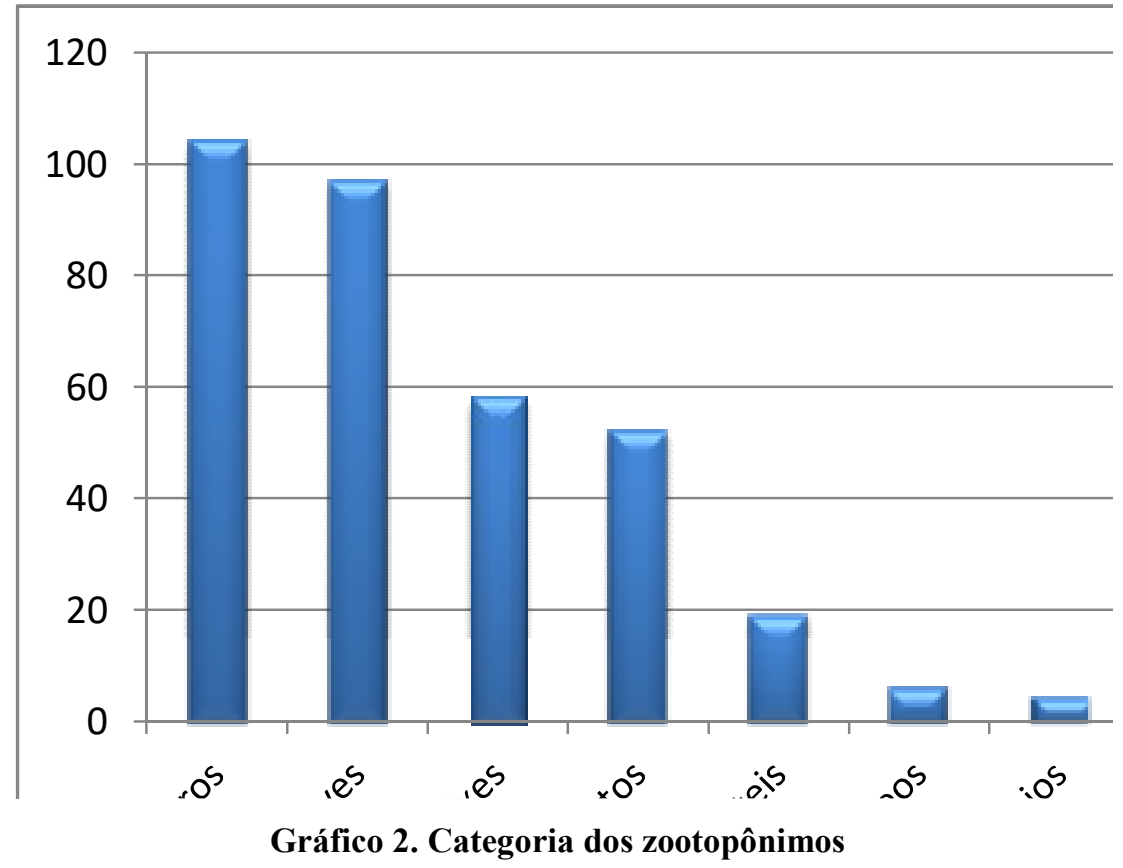


A família dos mamíferos é a mais representativa no cenário dos zootopônimos de Minas Gerais, com um número de 104 bases léxicas referentes a essa categoria. Em seguida, podemos verificar as aves, com 97 tipos distintos de nomes; peixes e insetos, com 58 e 52 tipos registrados; depois, com um menor número de tipos de bases léxicas, temos a família dos crustáceos (seis ocorrências), dos anfíbios (quatro ocorrências) e dos moluscos (duas ocorrências).

Dentre os 5.570 topônimos de caráter animal pesquisados, foi verificado que o topônimo com maior ocorrência no território mineiro foi o de origem francesa onça, referente a $23 \%$ dos zootopônimos, como pode ser constatado no gráfico a seguir, em que foram apresentadas as bases lexicais mais recorrentes em nossa pesquisa.

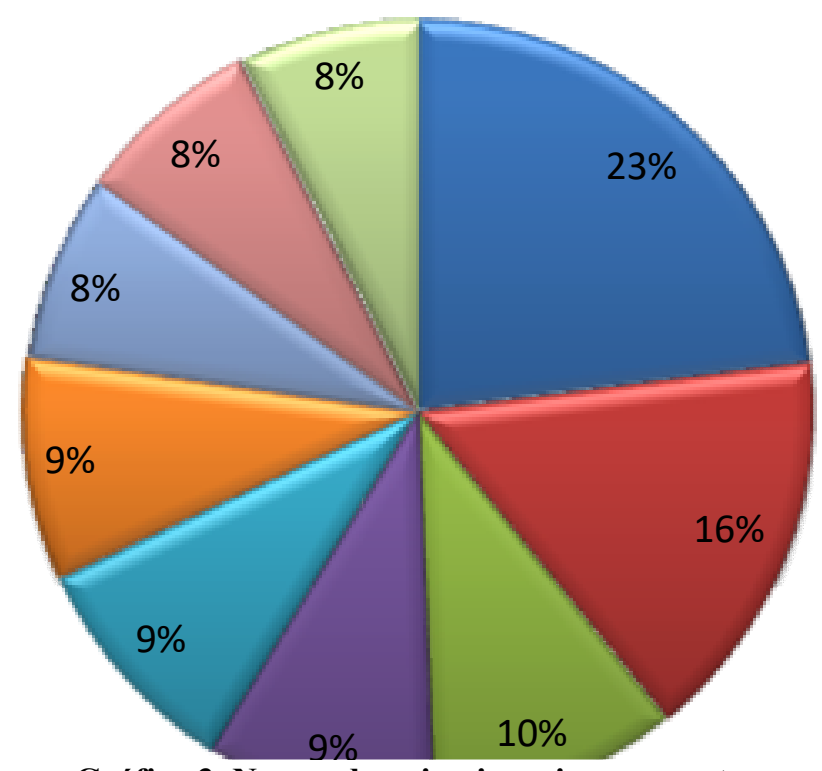

Gráfico 3. Nomes de animais mais recorrentes

\section{Considerações finais}

O presente trabalho teve como objetivo apresentar dados preliminares de pesquisa de doutorado em andamento, a fim de colaborar com os estudos toponímicos. A escolha pela análise de zootopônimos se deu pela grande variedade de nomes de índole animal no estado de Minas Gerais, que se relaciona diretamente com a história da formação do território mineiro, assim como a relação do homem com seu espaço.

\section{REFERÊNCIAS}

BIDERMAN, M. T. C. Dimensões da palavra. In: MEGALE, H. (Org.). Filologia e Linguística Portuguesa. n. 2. São Paulo: Humanitas, FFLCH/USP, 1998. p. 81-118.

As ciências do léxico. In: OLIVEIRA, A. M. P. P. de; ISQUERDO, A. N. As ciências do léxico: Lexicologia, Lexicografia, Terminologia. Campo Grande: Ed. da UFMS, 2001. 
. A estrutura mental do léxico. In: Estudos de Filologia. São Paulo: T. A. Queiroz/EDUSP, 1981.p. 131-145.

CARVALHINHOS, P. de J. Onomástica e lexicologia: o léxico toponímico como catalisador e fundo de memória. Estudo de caso: os sociotopônimos de Aveiro (Portugal). Revista da USP, São Paulo, n. 56, p. 172-179, dez./fev. 2002-2003.

CARVAlHINHOS, P. J.; ANTUNES, A. M. Princípios teóricos de toponímia e antroponímia: a questão do nome próprio. In: Cadernos do $C N L F$, v. XI, n. 02, [n.p.], 2007. Disponível em: <http://www.filologia.org.br/xicnlf/>. Acesso em: 10 fev. 2016.

CARVALHO, A. P. M. Hagiotoponímia em Minas Gerais. 2014. 822 f. Tese (Doutorado em Linguística) - Faculdade de Letras, Universidade Federal de Minas Gerais, Belo Horizonte, 2014.

COSERIU, E. O homem e sua linguagem. Rio de Janeiro: Presença, 1982.

CRISTIANINI, A. C.; ENCARNAÇÃO, M. R. T. A contribuição dos estudos sociogeolinguísticos para a escolha lexical na recepção e produção de textos orais e escritos. Cadernos do CNLF (CiFEFil), v. XII, p. 10-17, 2008.

CUNHA, A. G. da; MELLO SOBRINHO, C. Dicionário etimológico Nova Fronteira da língua portuguesa. Rio de Janeiro: Nova Fronteira, 1982.

DAUZAT, A. Les noms de lieux. Paris: Delagrave, 1926.

DICK, M. V. P. A. Métodos e Questões Terminológicas na Onomástica. Estudo de Caso: O Atlas Toponímico do Estado de São Paulo. In: Investigações Linguísticas e Teoria Literária. v. 9. Recife, UFPE: 1999. p. 119-148.

. Rede de conhecimento e campo lexical: hidrônimos e hidrotopônimos na onomástica brasileira. In: As Ciências do Léxico: lexicologia, lexicografia, terminologia. Campo Grande: Ed. da UFMS, 2004. p. 121-130.

Fundamentos Teóricos da Toponímia. Estudo de caso: o Projeto ATEMIG Atlas Toponímico do estado de Minas Gerais (variante regional do Atlas Toponímico do Brasil). In.: SEABRA, M. C. T. C. (Org.). O léxico em estudo. Belo Horizonte: Faculdade de Letras/UFMG, 2006. p. 91-117.

Toponímia e Antroponímia no Brasil. Coletânea de Estudos. 2. ed. São Paulo: FFLCH/USP, 1990.

DURANTI, A. Antropologia Linguística. Tradução espanhola de Pedro Tena. Madrid: Cambridge University Press, 2000.

FERREIRA, A. B. H. Novo dicionário da língua portuguesa. Rio de Janeiro: Editora Nova Fronteira, 1986.

GREGÓRIO, J. Contribuição Indígena ao Brasil. Juiz de Fora: Esdeva Empresa Gráfica Ltda, 1980 (3 volumes).

HOUAISS, A. Dicionário Eletrônico Houaiss da língua portuguesa. Editora Objetiva Ltda, 2007. 
ISQUERDO, A. N.; CASTIGLIONI, A. C. Em busca de modelo de dicionário onomástico toponímico. In: ISQUERDO, A. N.; FINATTO, M. J. B. As ciências do léxico: Lexicologia, Lexicografia, Terminologia. Campo Grande: Ed. da UFMS; Porto Alegre: Editora da UFRGS, 2010. p. 291-310.

KRIEGER, M. G. Lexicografia: o léxico no dicionário. In: SEABRA, M. C. T. C. de (Org.). O Léxico em Estudo. Belo Horizonte: Faculdade de Letras da UFMG, 2006. p.157-171.

LABOV, W. On the use of the present to explain the past. In: HEILMANN, L. Proceedings of the XIth International Congress of Linguistics. Bologna: Mulino, 1974. p. 825-851.

LYONS, J. Introdução à linguística teórica. São Paulo: Cia. Ed. Nacional, 1979.

MATORÉ, G. La méthode en lexicologie. Domaine Française. Paris: Didier, 1953.

OLIVEIRA, A. M. P. P. O Português do Brasil: brasileirismos e regionalismos. 1999. 475 f. Tese (Doutorado em Linguística e Língua Portuguesa) - Faculdade de Ciências e Letras, Universidade Estadual Paulista, Araraquara, 1999.

SALAZAR-QUIJADA, A. La Toponimia en Venezuela. Caracas: Universidad Central de Venezuela, Facultad de Ciencias Económicas y Sociales, 1985.

SAMPAIO, T. O Tupi na Geografia Nacional. 5. ed. São Paulo: Editora Nacional, 1987.

SAPIR, E. Linguística como ciência. Rio de Janeiro: Acadêmica, 1961.

SAUSSURE, F. Curso de Linguística Geral. 4. ed. São Paulo: Cultrix, 1972.

SEABRA, M. C. T. C. Referência e Onomástica. In: MAGALHÃES, J. S. de; TRAVAGLIA, L. C. (Org.). Múltiplas perspectivas em linguística: Anais do XI Simpósio Nacional e I Simpósio Internacional de Letras e Linguística (XI SILEL). Uberlândia: ILEEL, 2006. p. 1953-1960.

TARALLO, F. Pesquisa sociolinguística. 8. ed. São Paulo: Ática, 2007.

VASCONCELOS, J. L. Opúsculos: onomatologia. v. 3. Coimbra: Imprensa da Universidade, 1931.

Recebido em: 31/08/2016

Aprovado em: 27/03/2017 